\title{
B cells from African American lupus patients exhibit an activated phenotype
}

\author{
Laurence C. Menard, ${ }^{1}$ Sium Habte, ${ }^{1}$ Waldemar Gonsiorek, ${ }^{1}$ Deborah Lee, ${ }^{1}$ Dana Banas, ${ }^{1}$ \\ Deborah A. Holloway, ${ }^{1}$ Nataly Manjarrez-Orduno, ${ }^{1}$ Mark Cunningham, ${ }^{1}$ Dawn Stetsko, ${ }^{1}$ \\ Francesca Casano,, Selena Kansal, ${ }^{1}$ Patricia M. Davis, ${ }^{1}$ Julie Carman, ${ }^{1}$ Clarence K. Zhang, ${ }^{2}$ \\ Ferva Abidi, ${ }^{3}$ Richard Furie, ${ }^{3}$ Steven C. Nadler, ${ }^{1}$ and Suzanne J. Suchard ${ }^{1}$ \\ 'Discovery Translational Sciences, Bristol-Myers Squibb Company, Princeton, New Jersey, USA. 'Immunoscience \\ Translational Bioinformatics, Bristol-Myers Squibb Company, Pennington, New Jersey, USA. ${ }^{3}$ Division of Rheumatology, \\ Northwell Health, Great Neck, New York, USA.
}

\begin{abstract}
Systemic lupus erythematosus (SLE) is a complex systemic autoimmune disease driven by both innate and adaptive immune cells. African Americans tend to present with more severe disease at an earlier age compared with patients of European ancestry. In order to better understand the immunological differences between African American and European American patients, we analyzed the frequencies of $B$ cell subsets and the expression of $B$ cell activation markers from a total of 68 SLE patients and 69 normal healthy volunteers. We found that $B$ cells expressing the activation markers CD86, CD80, PD1, and CD40L, as well as CD19+CD27-lgD- double-negative B cells, were enriched in African American patients vs. patients of European ancestry. In addition to increased expression of CD40L, surface levels of CD40 on B cells were lower, suggesting the engagement of the CD40 pathway. In vitro experiments confirmed that CD40L expressed by B cells could lead to CD40 activation and internalization on adjacent $B$ cells. To conclude, these results indicate that, compared with European American patients, African American SLE patients present with a particularly active $B$ cell component, possibly via the activation of the CD40/CD40L pathway. These data may help guide the development of novel therapies.
\end{abstract}

Authorship note: S.G. Nadler and S.J. Suchard share senior authorship.

Conflict of interest: L.C. Menard, S. Habte, W. Gonsiorek, D. Lee, D. Banas, D.A. Holloway, N. Manjarrez-Orduno, M. Cunningham, D. Stetsko, F. Casano, S. Kansal, P.M. Davis, J. Carman, C.K. Zhang, S.C. Nadler, and S. Suchard are/were employees of Bristol-Myers Squibb. S. Habte, D. Lee, D. Banas, D.A. Holloway, M. Cunningham, D. Stetsko, J. Carman, S.G. Nadler, and S. Suchard own stocks of Bristol-Myers Squibb. R. Furie received funding from and is a consultant for Bristol-Myers Squibb.

Submitted: February 26, 2016 Accepted: May 11, 2016

Published: June 16, 2016

\section{Reference information:} JCI Insight. 2016;1(9):e87310. doi:10.1172/jci.insight.87310.

\section{Introduction}

Systemic lupus erythematosus (SLE) is a complex systemic disease that can affect multiple organs. Both innate and adaptive immune cells are involved in driving the disease (1). In particular, B cells and autoantibody production are believed to participate in the pathogenesis of SLE. Indeed, SLE is characterized by the presence of anti-nuclear antibodies (ANA), anti-dsDNA, anti-Smith antigen (Sm), or anti-ribonucleoprotein (RNP) antibodies, and disease activity and flares have been associated with the expansion of antibody-secreting cells (2).

SLE presentation varies greatly depending on the ancestral background. Compared with European Americans, African Americans are at higher risk of developing SLE and tend to be diagnosed earlier and suffer from a more severe disease with a higher rate of flares and progression to lupus nephritis (LN) and increased risk of death due to LN-related end-stage-renal disease. Although these disparities can be explained by the genetic background at disease onset, other factors such as poor socioeconomic status, lack of social support, or lower access to healthcare are major contributors to the accelerated and more severe course of disease (3-6). Little is known about the immunological mechanisms of SLE that could account for the variations in susceptibility and severity in different ethnic groups. African American and Hispanics with moderate to severe active SLE showed a better response to rituximab in a phase II/III trial (7). Also, a trend toward a better response with rituximab was seen in African American patients with LN (8). These data suggest a B cell-driven disease in these ethnic groups and imply that patients of different ancestries may respond differentially to treatments. In order to better understand mechanisms of disease and how they could be impacted by ancestral backgrounds, we analyzed the B cell compartment of African American and European American SLE patients and healthy volunteer controls. We discovered a distinct activated B cell signature in African American SLE patients with expansion of $\mathrm{CD}^{1} 9^{+} \mathrm{IgD}^{-} \mathrm{CD}_{27^{-}}$double-negative (DN) B cells, higher expression of CD86 and CD40 ligand (CD40L), and lower CD40 surface expression in B cells, suggestive of a constitutively active CD40 pathway in these patients. 
Table 1. Clinical data

\begin{tabular}{|c|c|c|}
\hline & African Americans $(n=29)$ & European Americans ( $n=39$ ) \\
\hline SLEDAI-2K, mean \pm SD & $3.8 \pm 2.6$ & $3.4 \pm 1.8$ \\
\hline Total ACR classification criteria, mean \pm SD & $5.7 \pm 1.2$ & $5.3 \pm 1.3$ \\
\hline Time since last flare (years), mean $\pm \mathrm{SD}$ & $2.9 \pm 4.3$ & $3.1 \pm 4.2$ \\
\hline \multicolumn{3}{|l|}{ Comorbidities } \\
\hline Nephritis, $n$ (\%) & $14(48)$ & $15(38)$ \\
\hline \multicolumn{3}{|l|}{ Medications } \\
\hline Hydroxychloroquine, $n$ (\%) & $15(52)$ & $18(46)$ \\
\hline Mycophenolate mofetil, $n$ (\%) & $10(34)$ & $14(36)$ \\
\hline Belimumab, $n(\%)$ & $3(10.3)$ & $1(2.6)$ \\
\hline Glucocorticoids, n (\%) & $23(79)$ & $19(49)$ \\
\hline
\end{tabular}

\section{Results}

Activated phenotype of B cells from African American SLE patients. We analyzed the expression of activation markers on B cells on 69 normal healthy volunteers (NHV) and 68 SLE patients, self-reported as either African or European ancestry. Disease activity, which was low to moderate; medications, except for glucocorticoid use (which was more prevalent in the African American group); and comorbidities were similar in the 2 ancestry groups (Table 1). Increased expression of the costimulatory molecule CD86 by SLE B cells has been previously described (9). We found an increased frequency of CD86-expressing B cells, both in the $\mathrm{CD}_{27}{ }^{-}$and $\mathrm{CD} 27^{+}$compartments in African American patients (average percentages of CD $86^{+}$cells: $11 \%$ of $\mathrm{CD} 27^{-} \mathrm{B}$ cells and $16 \%$ of $\mathrm{CD} 27^{+} \mathrm{B}$ cells), compared with NHV of either ancestry (average percentages of CD $86^{+}$cells: $1.5 \%$ of CD27- B cells and $6 \%-9 \%$ of $\mathrm{CD} 27^{+} \mathrm{B}$ cells) or SLE patients of European ancestry (average percentages of $\mathrm{CD}^{2} 6^{+}$cells: $2.7 \%$ of $\mathrm{CD} 27^{-} \mathrm{B}$ cells and $9 \%$ of $\mathrm{CD} 27^{+} \mathrm{B}$ cells) (Figure 1). Surprisingly, there was no significant increase in the frequency of $\mathrm{CD} 86^{+} \mathrm{B}$ cells in SLE patients of European descent relative to NHV, suggesting that African American patients may largely account for the previously described increase in CD86 expression by B cells in SLE (Figure 1).

We also analyzed the expression of CD80 and programmed cell death protein 1 (PD1), which are upregulated on B cells upon activation (10) (Supplemental Figure 4; supplemental material available online with this article; doi:10.1172/jci.insight.87310DS1). Both CD80 and PD1 were significantly upregulated on $\mathrm{CD}_{27}$ B cells from African American SLE patients compared with European American SLE patients and all NHV groups (Supplemental Figure 1, A and C). Interestingly, neither PD1 nor CD80 were upregulated in CD27- B cells from European American SLE patients compared with NHV. Finally, PD1 but not CD80 was upregulated in CD27 $7^{+}$memory B cells of both ancestral groups of SLE patients compared with their respective NHV controls (Supplemental Figure 1, B and D).

Increased CD40L and decreased CD40 surface expression on B cells from African American SLE patients. CD40L was shown to be increased in SLE T and B cells (11-13). We found increased expression of CD40L by CD27- B cells, not by CD27 ${ }^{+} \mathrm{B}$ cells, in our SLE cohort compared with NHV (Figure 2). Moreover, the frequency of $\mathrm{CD} 40 \mathrm{~L}^{+} \mathrm{CD} 27^{-} \mathrm{B}$ cells was increased in African American SLE patients (average: $5.7 \%$ of $\mathrm{CD} 40 \mathrm{~L}^{+} \mathrm{CD} 27^{-} \mathrm{B}$ cells) compared with European American SLE patients (average: $2.1 \%$ of $\mathrm{CD} 40 \mathrm{~L}^{+} \mathrm{CD}^{2} 7^{-}$ B cells, $P<0.02$ ). Analysis of CD40L expression on T cells revealed a modest but significant increase in African American SLE naive CD45RO-CD4 ${ }^{+}$and $\mathrm{CD}^{-} 5 \mathrm{RO}^{-} \mathrm{CD} 8^{+} \mathrm{T}$ cells compared with NHV (Supplemental Figure 2). CD40L can also be found in a soluble form (sCD40L), which is elevated in SLE and has the potential to activate B cells (14). In our cohort, we did not observe an increase in plasma levels of sCD40L in SLE patients. In fact, African American SLE patients showed reduced levels of sCD40L compared with European American NHV and SLE patients (Supplemental Figure 3).

CD40, the receptor for CD40L, is constitutively expressed on B cells. We observed that, in some patients, a subset of B cells expressed lower levels of surface CD40 (CD40 $0^{\text {lo }} \mathrm{B}$ cells) (Figure 3A). There was a major 
A Isotype control

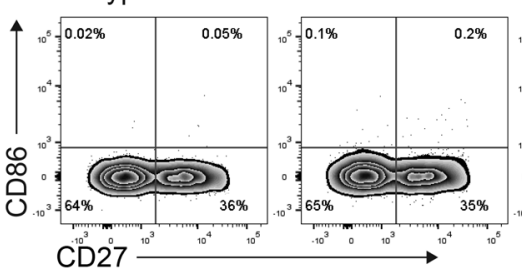

SLE (Eur. Am.)

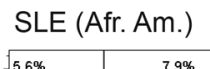

B

CD27- B cells

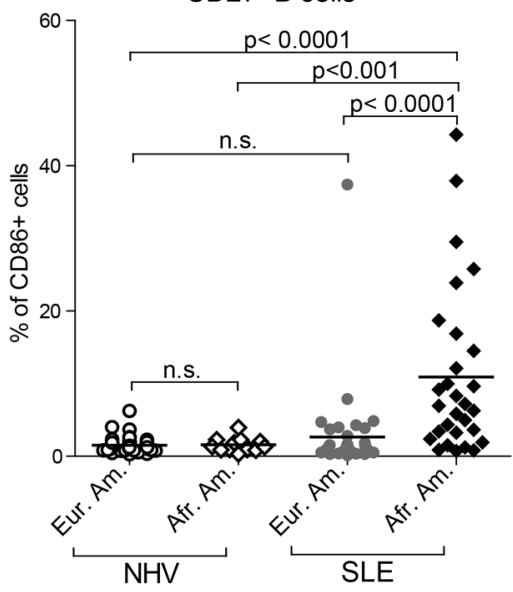

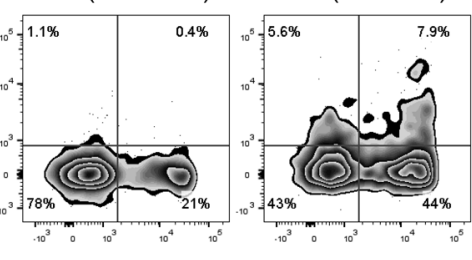

c

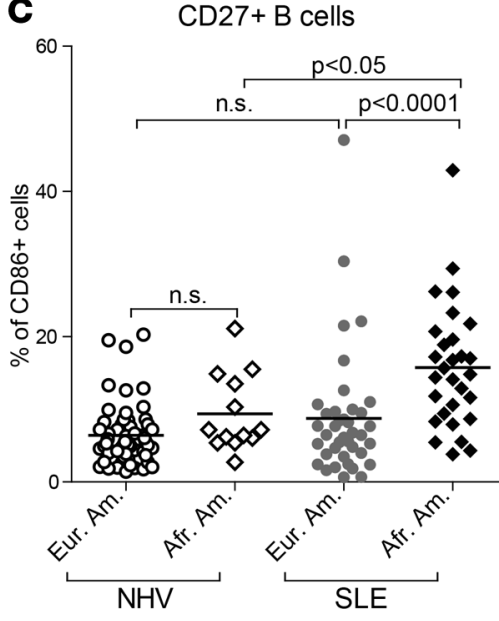

Figure 1. Increased frequency of CD86 $B$ cells in African American (Afr. Am.) systemic lupus erythematosus (SLE) patients. (A) Representative zebra plot of CD86 and CD27 expression on CD19+ total B cells from peripheral blood mononuclear cells of a normal healthy volunteer (NHV) and SLE European American (Eur. Am.) and Afr. Am. patients. Numbers on zebra plots represent percentages of cells in each quadrant. (B and C) Summarized frequencies of CD86 ${ }^{+}$CD27- B cells (B) or CD86 ${ }^{+}$CD27 $7^{+}$memory B cells (C) in 56 Eur. Am. and 13 Afr. Am. NHV donors and 39 Eur. Am. and 29 Afr. Am. SLE patients. The horizontal bars represent the average for each group. $P$ values are indicated (Mann-Whitney test).

increase in the frequency of these $\mathrm{CD} 40^{\mathrm{lo}} \mathrm{CD} 27^{-} \mathrm{B}$ cells in African American SLE patients (average: 9.3\% of $\mathrm{CD} 40^{\mathrm{lo}} \mathrm{CD} 27^{-} \mathrm{B}$ cells) compared with European American SLE patients (average: $2.8 \%, P<0.002$ ) or African American NHV (average: $0.9 \%, P<0.005$ ) (Figure $3 \mathrm{~B}$ ). CD $40^{\mathrm{lo}} \mathrm{CD} 27^{-} \mathrm{B}$ cells were also increased in SLE patients of European descent (average: 2.8\%) versus NHV (average: $0.7 \%, P<0.0005$ ) but to a lesser extent than in African American patients (Figure 3B). We observed a similar trend in $\mathrm{CD} 27^{+} \mathrm{B}$ cells, with slightly increased frequencies of $\mathrm{CD} 40^{\mathrm{lo}} \mathrm{CD} 27^{+} \mathrm{B}$ cells in SLE patients versus NHV of the same ancestral

background, and in African American (average: 3.1\%) versus European American SLE patients (average: $1.9 \%, P<0.02$ ) (Figure 3C).

We then determined whether the same patients harbored both $\mathrm{CD} 40^{\text {lo }} \mathrm{B}$ cells and $\mathrm{CD} 40 \mathrm{~L}^{+} \mathrm{B}$ cells. There was a good correlation between the frequencies of $\mathrm{CD} 40^{\text {lo }} \mathrm{B}$ cells and $\mathrm{CD} 40 \mathrm{~L}^{+} \mathrm{B}$ cells in African American patients (Spearman $r=0.6853, P<0.0005$ ) (Figure 3D), which suggested the possibility of $\mathrm{B}$ cell-B cell interactions mediated by CD40 and CD40L (15). On the other hand, the correlation between frequencies of $\mathrm{CD} 40^{\mathrm{lo}}$ and $\mathrm{CD} 40 \mathrm{~L}^{+} \mathrm{B}$ cells was weaker in European American patients (Spearman $r=$ $0.4313, P<0.02$ ) (Figure $3 \mathrm{E}$ ). There was no correlation between the frequencies of $\mathrm{CD} 40^{\text {lo }} \mathrm{B}$ cells and the frequencies of $\mathrm{CD} 40 \mathrm{~L}^{+} \mathrm{CD} 4{ }^{+} \mathrm{CD} 45 \mathrm{RO}^{-} \mathrm{T}$ cells and $\mathrm{CD} 40 \mathrm{~L}^{+} \mathrm{CD} 8{ }^{+} \mathrm{CD} 45 \mathrm{RO}^{-} \mathrm{T}$ cells in SLE patients, independent of ancestry (Spearman $r=0.084, P=0.55$, and Spearman $r=0.151, P=0.29$, respectively). In addition, we did not find an association between the lower plasma levels of sCD40L and higher frequencies of $\mathrm{CD} 40^{\mathrm{lo}} \mathrm{B}$ cells in African Americans.

CD40L binding to CD40 leads to CD40 internalization. Engagement of CD40 on murine B cells by sCD40L leads to rapid loss of surface CD40 expression by receptor internalization (16-18). To test whether CD40L expressed by B cells could engage CD40 on B cells and explain the phenotype observed in SLE African American patients, we cultured purified B cells from NHV with soluble CD40L-isoleucine zipper (CD40LIZ) or anti-IgM F(ab') $)_{2}$. Within 3 hours, we observed the appearance of CD40 $0^{\text {lo }} \mathrm{B}$ cells in wells cultured with CD40L-IZ but not with anti-IgM F(ab') stimulation. Expression of CD86 was upregulated by CD40L-IZ at 24 hours, similar to what was seen with anti-IgM F(ab') (Figure 4A) (Supplemental Figure 4), which confirmed activation of $\mathrm{B}$ cells under both conditions.

In order to visualize internalization of CD40, we used an Amnis ImageStream that combines fluorescence microscopy with the throughput and power of quantification of a flow cytometer. Freshly isolated NHV B cells display a regular ring-shaped pattern of CD40 staining on the surface (Figure 5A). Prior to stimulation, cells were stained with anti-CD40-PE at $4^{\circ} \mathrm{C}$. Upon a short stimulation (1 hour) with CD40L$\mathrm{IZ}$ at $37^{\circ} \mathrm{C}$, the $\mathrm{CD} 40$ staining became punctuate, characteristic of aggregation and internalization (Figure $5 B)$. Internalization was quantified with the internalization feature in the IDEAS software (19), which measures the ratio of fluorescence intensity inside the cell (as defined by a 4-pixel erosion of the bright field of the entire cell) to the fluorescence intensity of the entire cell (as defined by the bright field). This ratio is mapped to a log scale; therefore, a positive value means medium to high internalization, whereas a negative value means no to low internalization. Unstimulated freshly isolated B cells display an average internal- 

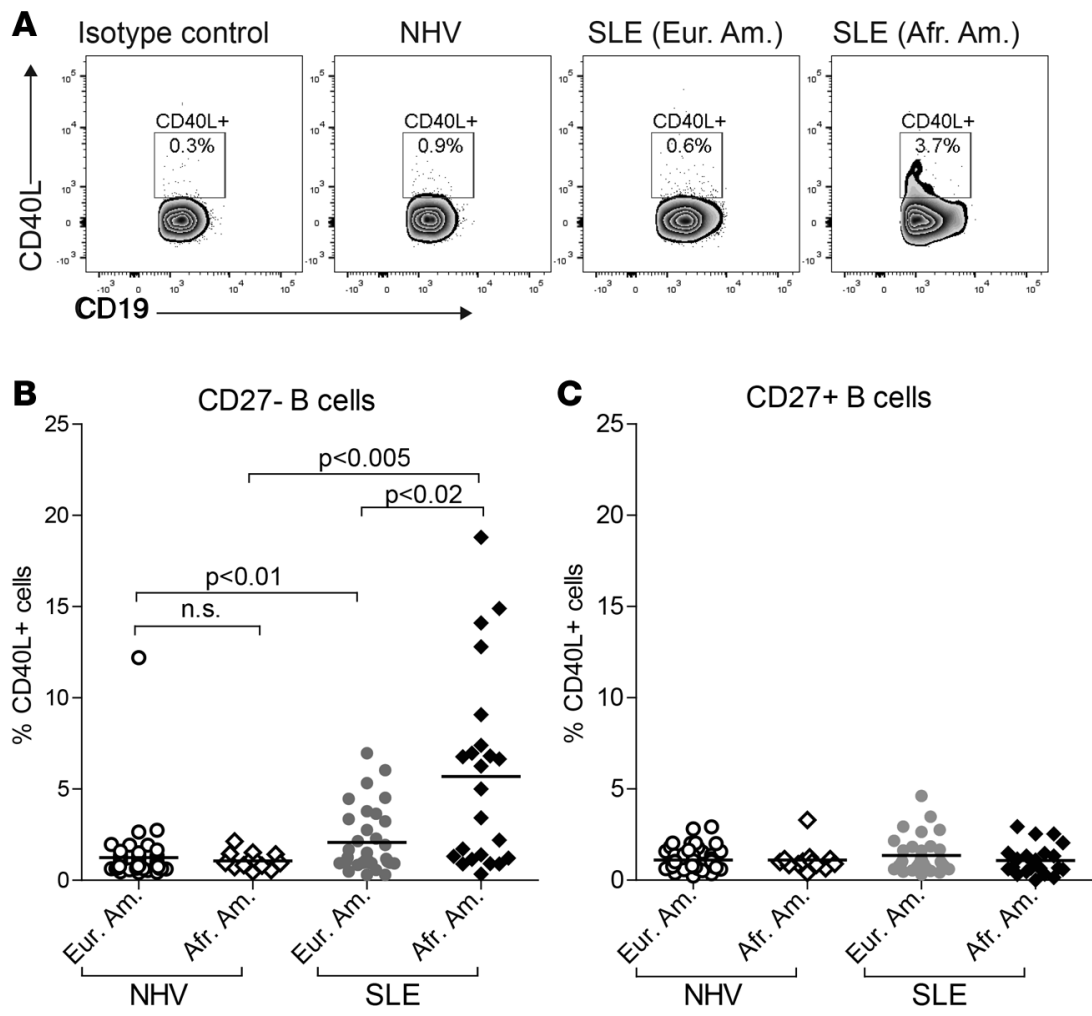

Figure 2. Higher frequencies of CD40 ligand (CD40L)+ $B$ cells in African American (Afr. Am.) systemic lupus erythematosus (SLE) patients. (A) Representative zebra plot of CD4OL expression on $\mathrm{CD}^{19}{ }^{+} \mathrm{CD} 27^{-} \mathrm{B}$ cells from peripheral blood mononuclear cells of a normal healthy volunteer (NHV) and European American (Eur. Am.) and Afr. Am. SLE patients. Numbers on zebra plots represent frequencies of $C D 40 L^{+} C D 27-B$ cells. (B and C) Summarized frequencies of CD4OL ${ }^{+}$CD27- B cells (B) or CD40L ${ }^{+} \mathrm{CD} 27^{+} \mathrm{B}$ cells (C) in 55 Eur. Am. and $13 \mathrm{Afr}$ Am. NHV donors and 34 Eur. Am. and 23 Afr. Am. SLE patients. The horizontal bars represent the average for each group. $P$ values are indicated (Mann-Whitney test)

ization score of 0.41 (Figure 5, D and G). Upon a 1-hour stimulation with CD40L-IZ, the average internalization score was increased more than 5 times to $2.09(P<0.05)$ (Figure 5, D and G). By contrast, CD45, which is not internalized following CD40L-IZ stimulation, had an average internalization score of 0.67 in unstimulated cells and 0.68 in CD40L-IZ-stimulated B cells $(P=1.00)$ (Figure 5, E and G). Using an internalization score cutoff of 2.5, based on a low frequency of B cells with internalized CD40 in an unstimulated sample $(2.1 \%)$, we determined that $42 \%$ of B cells had internalized CD40 after CD40L-IZ stimulation

(Figure 5H). Preincubating cells with CD40L-IZ, in addition to anti-CD40-PE, at $4^{\circ} \mathrm{C}$ did not affect CD40 staining and internalization, showing that CD40L-IZ does not block binding of anti-CD40-PE to CD40 (Supplemental Figure 5). Therefore, we confirmed that the rapid loss of CD40 on the surface of B cells following CD40 triggering was due to CD40L-mediated internalization. African American SLE patients had increased expression of surface CD40L concomitant to the lower expression of CD40 on B cells. We then went on to confirm that a membrane form of CD40L could lead to CD40 internalization, using Chinese hamster ovary (CHO) cells stably transfected with human CD40L (hCD40L-CHO). Purified B cells showed downregulation of surface CD40 expression following a 1-hour coincubation with hCD40L-CHO cells (Figure 4B). The extent of surface CD40 downregulation was dependent on the number of hCD40LCHO cells: $10 \%$ of hCD $40 \mathrm{~L}-\mathrm{CHO}$ cells led to $37 \%$ total CD $40^{\mathrm{lo} /-} \mathrm{B}$ cells, whereas $1 \%$ of hCD $40-\mathrm{CHO}$ cells induced CD40 downregulation in only $5 \%$ of B cells. CD86 was upregulated in B cells cocultured with hCD40L-CHO cells at 24 hours, confirming their activation (Figure 4B). The decrease in CD40 surface expression on B cells cocultured with hCD40L-CHO cells was not transient, as in B cells stimulated with CD40L-IZ, likely because of the constitutive expression of CD40L by the CHO cells. CD40 internalization on B cells following coculture with 10\% hCD40L-CHO cells was confirmed by Amnis ImageStream and was similar to CD40L-IZ stimulation (Figure 5, C, D, G, and H) (average internalization score: $1.69[P<$ 0.05 vs. unstimulated], $33 \%$ of cells with $C D 40$ internalization $[P<0.05$ vs. unstimulated]).

CD40 engagement leads to activation of multiple pathways, including the NF- $\kappa$ B pathway. We therefore quantified the nuclear translocation of the NF- $\mathrm{KB}$ p50 subunit following CD40 activation using the similarity feature, which measures the similarity of p50 NF- $\kappa \mathrm{B}$ fluorescence to 7-aminoactinomycin $\mathrm{D}$ (7-AAD) nuclear staining (20). We used a cutoff of similarity greater than 0 for $\mathrm{NF}-\kappa \mathrm{B}$ nuclear translocation. Unstimulated cells (29\%) had some degree of nuclear translocation (Figure 5, A, F, and I). After stimulation with CD40L-IZ and hCD40L-CHO cells, the frequency of cells presenting with p50 nuclear translocation was greatly increased $(58 \%[P<0.05]$ and $54 \%[P<0.05]$, respectively) (Figure 5, B, C, F, and I). In conclusion, CD40 stimulation of B cells with CD40L-IZ or hCD40L-CHO cells induced both CD40 internalization and downstream signaling.

CD40L upregulated on B cells can trigger CD40 activation on adjacent B cells in a feed-forward loop. We then sought to induce CD40L expression on B cells. Stimulation of purified B cells for 3 days with CD40L-IZ led to upregulation of CD40L, concomitant to CD86 upregulation (Figure 6A). In contrast, B cells stimu- 
A Isotype control

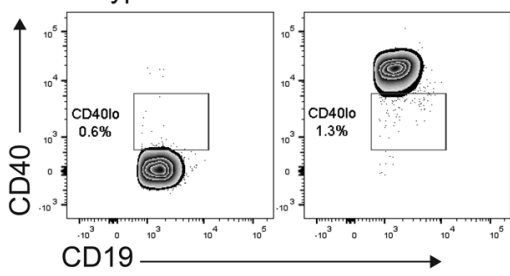

B

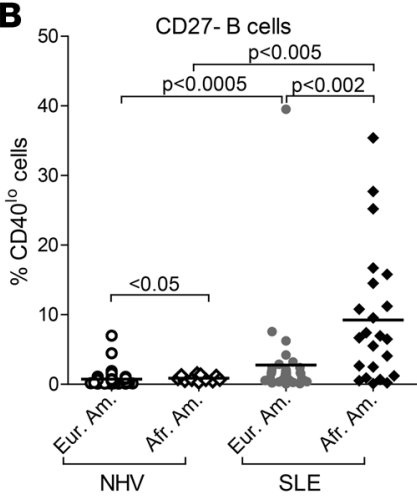

D

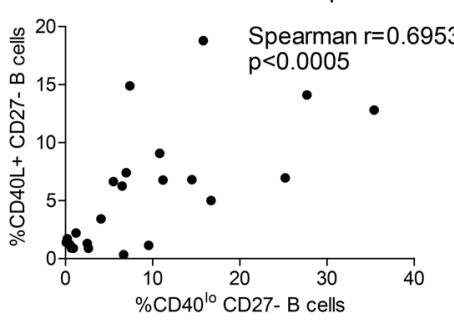

SLE (Eur. Am.)

SLE (Afr. Am.)
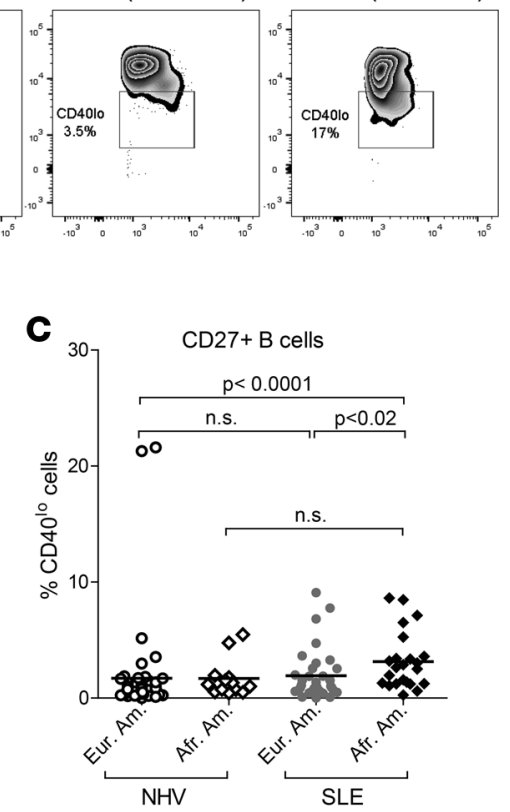

E European American SLE patients

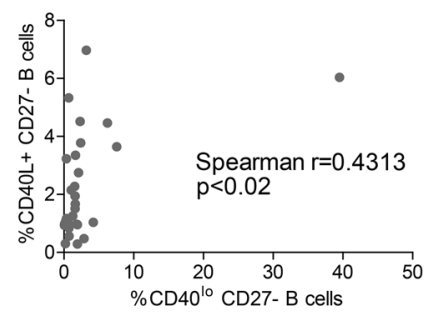

Figure 3. African American (Afr. Am.) systemic lupus erythematosus (SLE) patients express lower levels of surface CD40 on their B cells. (A) Representative zebra plot of CD40 expression by CD19+CD27- B cells from peripheral blood mononuclear cells of a normal healthy volunteer (NHV) and European American (Eur. Am.) and Afr. Am. SLE patients. Numbers on zebra plots represent frequencies of $B$ cells with low surface CD40 expression (CD40 ${ }^{10}$ ). (B and C) Summarized frequencies of $\mathrm{CD} 40^{10} \mathrm{CD} 27^{-} \mathrm{B}$ cells (B) and CD40 ${ }^{10} \mathrm{CD} 27^{+} \mathrm{B}$ cells (C) in 55 Eur. Am. and 13 Afr. Am. NHV donors and 34 Eur. Am. and 23 Afr. Am. SLE patients. The horizontal bars represent the average for each group. $P$ values are indicated (Mann-Whitney test). ( $\mathbf{D}$ and $\mathbf{E})$ Spearman correlation between frequencies of CD4OL ${ }^{+} \mathrm{CD} 27^{-} \mathrm{B}$ cells and $\mathrm{CD} 40^{\circ} \mathrm{CD} 27^{-} \mathrm{B}$ cells in 23 Afr. Am. (D) and 34 Eur. Am. (E) patients. Spearman $r$ and $P$ values are indicated on each plot.

lated through TLR9 with CpG upregulated CD86 but very little CD40L (Figure 6A).

We then explored if CD40L upregulated on B cells could induce CD40 internalization and NF- $\kappa \mathrm{B}$ translocation. We cultured purified NHV B cells with CD40L-IZ or $\mathrm{CpG}$ for 3 days and confirmed CD40L upregulation in the cells cultured with CD40L-IZ. The CpG- and CD40LIZ-stimulated B cells were then washed and cocultured with freshly isolated $B$ cells from the same donors at a 1:1 ratio. The fresh $\mathrm{B}$ cells were labeled with anti-CD40-PE (to follow CD40 internalization) and with anti-CD45APC-Cy7, which allowed us to distinguish them from the CpG- or CD40L-IZ-stimulated B cells. After 1 hour of coculture, we analyzed CD40 internalization and p50 $\mathrm{NF}-\kappa \mathrm{B}$ translocation on the CD45-APC-Cy7-labeled B cells. B cells that had been cultured with CD40L-IZ and

had upregulated CD40L were able to induce CD40 internalization on freshly isolated autologous B cells (average internalization score of 1.26 vs. 0.41 in unstimulated cells, $P<0.05 ; 19.5 \%$ of cells with internalized CD40 vs. $2.1 \%$ in unstimulated cells, $P<0.05$ ) (Figure 6, B, D, and E). By contrast, CpG-stimulated $\mathrm{B}$ cells, which only marginally augmented CD40L expression, did not induce CD40 internalization (average internalization score of $0.46,2.7 \%$ of cells with internalized CD 40 ) (Figure 6, B, D, and E). We also observed a small increase in p50 nuclear translocation in B cells cocultured with CD40L-IZ-stimulated B cells (average: $41 \%)$ that reached statistical significance $(P<0.05)$. The same was not seen with $\mathrm{CpG}$ stimulated B cells (average: 27\%) (Figure 6, C and F). In conclusion, we demonstrated that, upon CD40 triggering, B cells upregulated CD40L, which was able to induce CD40 internalization and activation in trans on adjacent $B$ cells, thereby creating a feed-forward loop.

Increased $D N$ IgD $C D 27^{-} B$ cell frequencies in African American SLE patients. In order to determine if the activated phenotype of B cells from African American SLE patients could potentially result in dysregulated B cell subsets and B cell-driven autoimmunity, we analyzed the frequencies of B cell populations in a subgroup of our cohort that contained 21 African American patients and 21 European American patients. Patient characteristics (disease scores, medications, comorbidities) were similar in this subgroup and the original cohort (Supplemental Table 1). This analysis of cell subset frequencies was performed on whole blood. We found that, in addition to being increased in all SLE patients compared with NHV, as previously reported (21-23), $\mathrm{DN} \mathrm{CD} 19^{+} \mathrm{CD} 27^{-} \mathrm{IgD}^{-} \mathrm{B}$ cells were greatly enriched in African American patients (Figure 7A). Doublets and $\mathrm{CD}^{+} \mathrm{T}$ cells were excluded from the $\mathrm{B}$ cell subset analysis (Supplemental Figure 6). $\mathrm{CD} 19^{+} \mathrm{CD} 27^{+} \mathrm{IgD}^{+}$unswitched memory B cells, on the other hand, were underrepresented in African American patients versus patients of European ancestry and NHV (Figure 7C). The frequencies of $\mathrm{CD} 19^{+} \mathrm{CD} 27^{+} \mathrm{IgD}^{-}$switched memory B cells were similar in SLE patients and NHV of the same ancestries. In fact, switched memory B cells were increased in frequency in African American individuals, regardless of whether they were healthy controls or SLE patients (Figure 7D). Naive B cell frequencies were 
A

A No stim

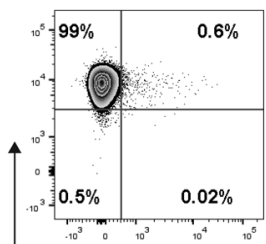

$3 \mathrm{~h}$

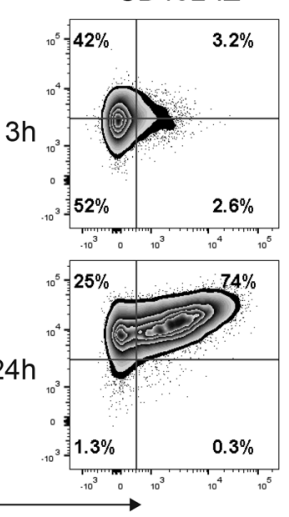

CD40L-IZ
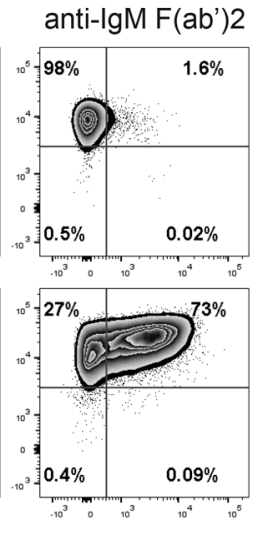

CD86

B

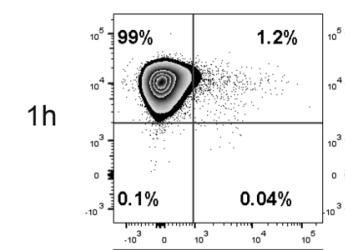

CD40L-IZ
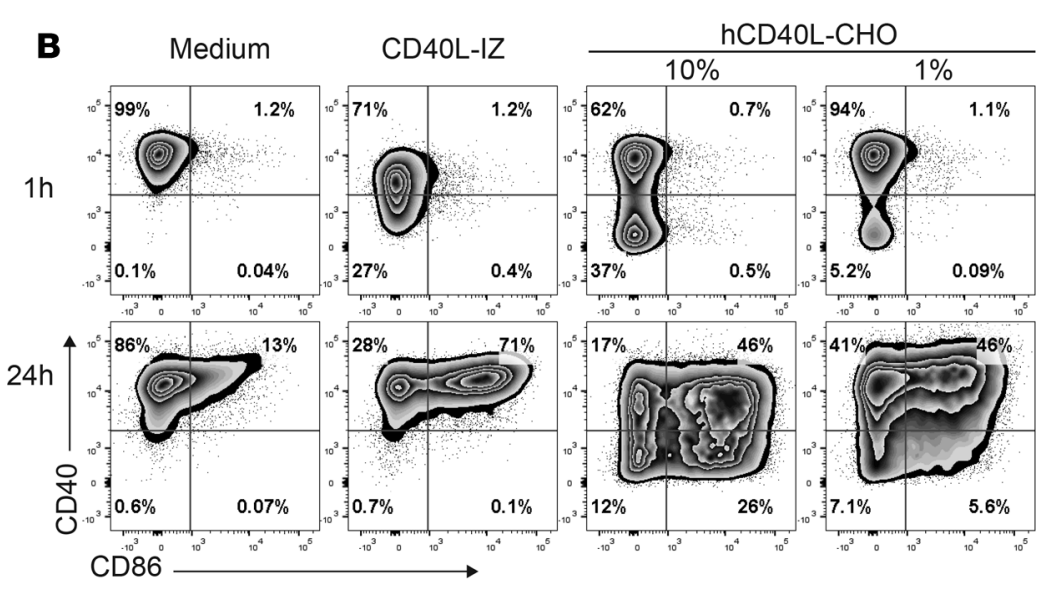

Figure 4. Rapid downregulation of surface $C D 40$ in $B$ cells activated by CD40 ligand (CD40L). (A) CD86 and CD40 expression in freshly isolated CD19+ $\mathrm{B}$ cells from a normal healthy volunteer (NHV) and after stimulation with soluble CD4OL-isoleucine zipper (CD4OL-IZ) or anti-IgM F(ab') for 3 hours and 24 hours. (B) CD86 and CD40 expression in isolated CD19+ $B$ cells from a NHV cultured for 1 hour or 24 hours in medium only, with CD4OL-IZ, or with $1 \%$ or $10 \%$ of CHO cells stably transfected with human CD4OLC (hCD4OL-CHO). Numbers on zebra plots represent percentages of cells in each quadrant. Experiments were performed at least twice using 2 donors per experiment.

reduced in all African American individuals compared with European Americans, with no differences between SLE and NHV (Figure 7B). Except for a slight decrease of $\mathrm{CD} 4^{+} \mathrm{T}$ cell frequencies in African American patients, other immune cell subsets (monocytes, NK cells, subsets of helper T cells) were not differentially distributed in the 2 ancestral backgrounds (Supplemental Table 2).

$\mathrm{CD}^{-} 7^{-} \mathrm{B}$ cells contain both naive $\mathrm{IgD}^{+}$and $\mathrm{DN}$ IgD $^{-} \mathrm{B}$ cells. $\mathrm{IgD}^{+}$represent on average $88 \%$ and $67 \%$ of CD27- B cells in SLE patients of European and African ancestries respectively. To rule out that the increased frequencies of DN B cells in African American patients could explain the increased frequencies of $\mathrm{CD}^{\circ} 6^{+} \mathrm{CD} 27^{-} \mathrm{B}$ cells described in Figure 1 , we compared the expression of $\mathrm{CD} 86$ by $\mathrm{CD} 27-\mathrm{IgD}^{+}$(naive) and $\mathrm{CD}_{27}-\mathrm{IgD} \mathrm{D}^{-}(\mathrm{DN}) \mathrm{B}$ cells. Even though $\mathrm{DN}$ B cells express more $\mathrm{CD} 86$ than naive $\mathrm{B}$ cells, both $\mathrm{IgD}^{+}$and $\mathrm{IgD}^{-} \mathrm{CD} 27^{-} \mathrm{B}$ cells displayed an increase in the percent of $\mathrm{CD} 86^{+}$cells in African Americans versus European Americans (Supplemental Figure 7).

African ancestry is the strongest factor associated with the increased activated B cell phenotype observed in SLE patients. To independently confirm that self-reported African American ancestry was the main factor associated with the differences in B cell phenotypes, rather than other confounding factors such as medication, we performed multiple linear regression analyses over a total of 15 demographic and clinical factors, including sex, age, duration of disease, disease scores, comorbidities, and clinical treatment (detailed in Methods). For all $6 \mathrm{~B}$ cell phenotypic endpoints tested as response variables (\% of DN, CD86 ${ }^{+} \mathrm{CD} 27^{-}$,

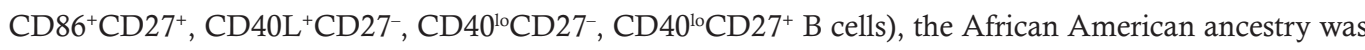
the strongest variable associated (Table 2). Other variables more weakly associated with these parameters include the total count of ACR criteria associated with the percentage of DN B cells and glucocorticoid use associated with increased percentages of $\mathrm{CD} 86^{+} \mathrm{CD} 27^{-}$and $\mathrm{CD} 86^{+} \mathrm{CD} 27^{+} \mathrm{B}$ cells. This suggests that glucocorticoid use is linked to the frequencies of $\mathrm{CD} 86^{+} \mathrm{CD} 27^{-}$and $\mathrm{CD} 86^{+} \mathrm{CD} 27^{+} \mathrm{B}$ cells to a lesser extent than African American ancestry. Although glucocorticoids have been previously shown to increase CD40L expression by lymphocytes (24), we could not identify an effect of glucocorticoid use on the

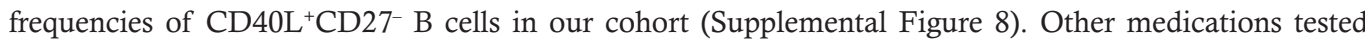
(hydroxychloroquine and mycophenolate mofetil) were not correlated with any of the measured B cell endpoints. Some factors had a negative predictive value, such as duration of disease for the frequencies of $\mathrm{CD} 86^{+} \mathrm{CD} 27^{-} \mathrm{B}$ cells and the presence of discoid rash in the African American population for the percentages of $\mathrm{CD} 40 \mathrm{~L}^{+} \mathrm{CD} 27^{-} \mathrm{B}$ cells. To conclude, the $\mathrm{B}$ cell phenotype observed in African American patients is unlikely due to differences in medication.

Although SLEDAI-2k was not identified as a confounding factor for the activated B cell phenotype, we observed a moderate correlation between SLEDAI-2k and the percentage of $\mathrm{CD} 86^{+} \mathrm{CD} 27^{-} \mathrm{B}$ cells in African American SLE patients (Supplemental Figure 9A). To ensure that the activated B cell phenotype harbored by these patients was not a result of previous flares, we compared - for each ancestral background - the frequencies of B cells with an activated phenotype in patients who recently flared versus those who 

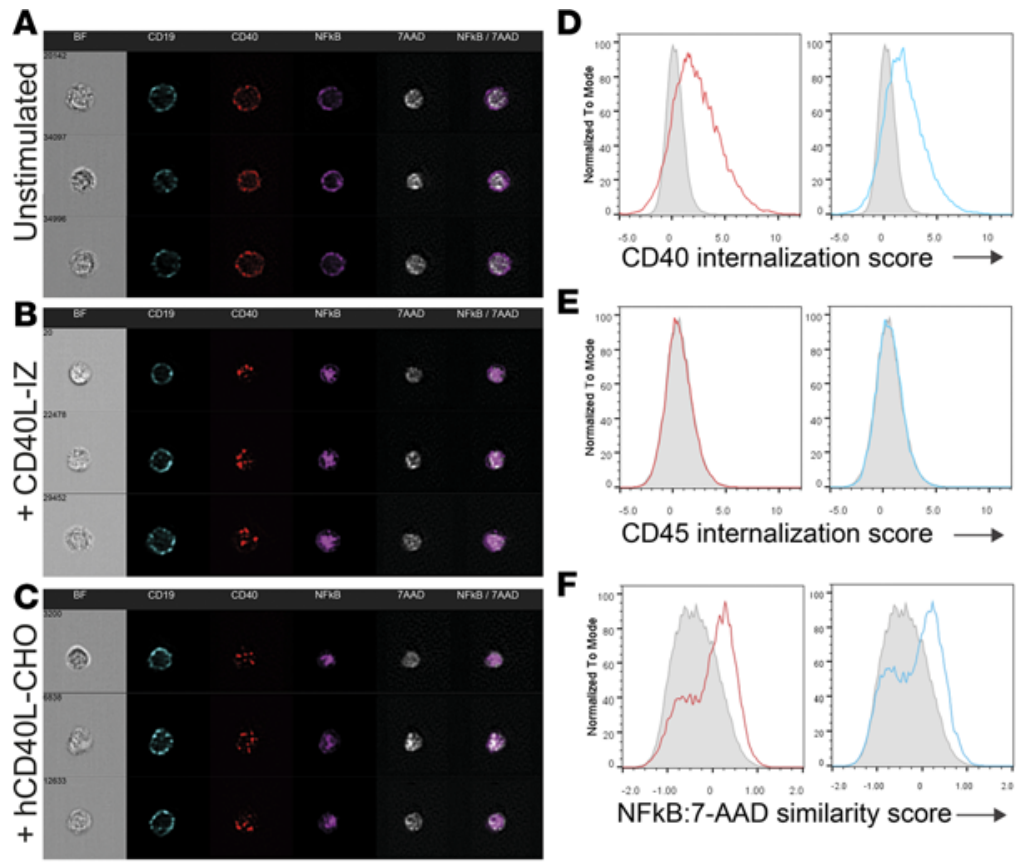

E
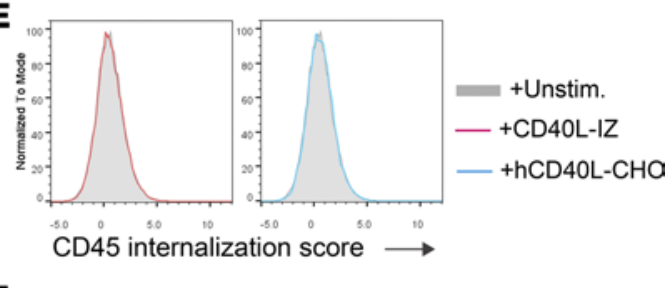

$\mathbf{F}$
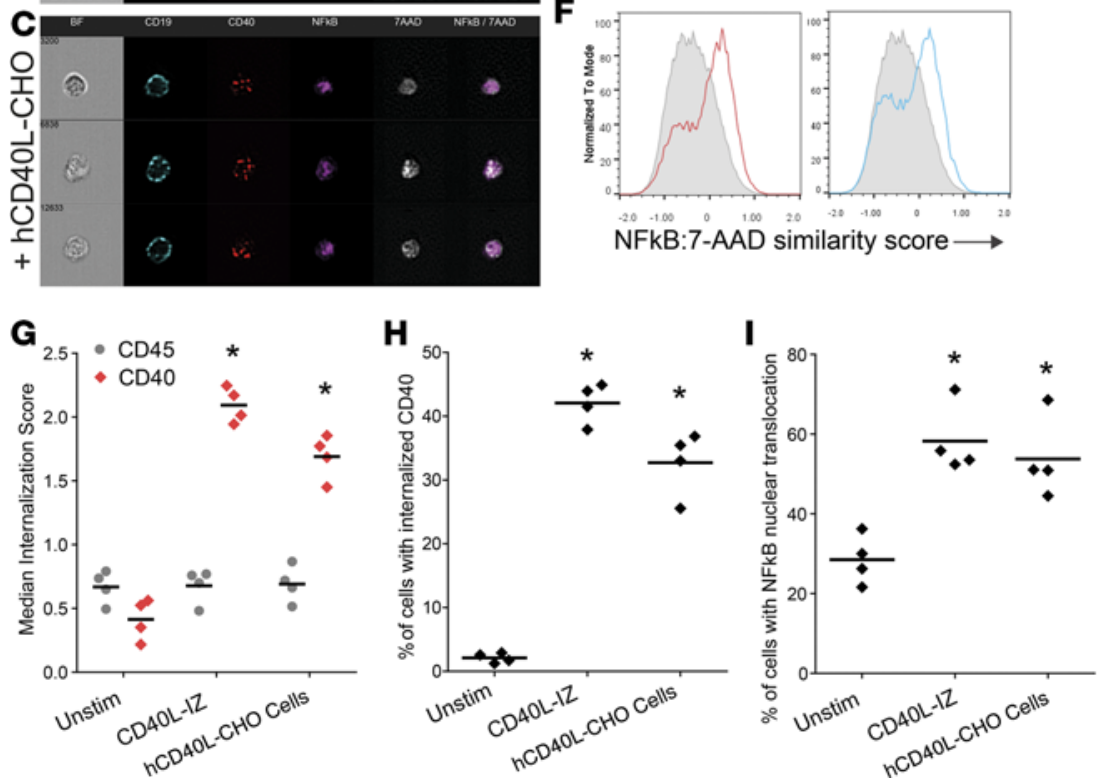

Figure 5. Internalization of CD40 following engagement with $\mathrm{CD} 40$ ligand (CD4OL).

(A-C) Representative pictures of CD19, CD40, NF- $\kappa B$, and nuclear 7-aminoactinomycin (7-AAD) stainings in unstimulated $B$ cells ( $A$ ), B cells stimulated with soluble CD40L-isoleucine zipper (CD4OL-IZ) (B), or CHO cells stably transfected with human CD4OLG (hCD4OL-CHO) (C) for 1 hour. (D-F) histograms representing CD40 internalization (D), CD45 internalization (E), and NF- $\kappa B$ nuclear translocation (defined as the similarity score between NF- $\mathrm{KB}$ and 7-AAD staining) (F) in unstimulated $B$ cells (Unstim, gray), CD4OL-IZ-stimulated B cells (red), or hCD4OL-CHO cell-stimulated $B$ cells (blue). (G-I) Internalization score of CD40 (red) and CD45 (gray) (G), percentage of cells with internalized CD40 (internalization score $>2.5)(H)$, and percentage of $B$ cells with p50 NF- $\kappa B$ nuclear translocation (NF-אB:7-AAD similarity score $>0$ ) (I). Averaged results from 2 donors from 4 different experiments are represented on the graphs. The horizontal bars represent the average of 4 experiments for each stimulation condition. ${ }^{*} P<0.05$ by Mann-Whitney test vs. unstimulated $B$ cells (Unstim) (G-I). Purified total B cells from normal healthy volunteers were used.

did not. Frequencies of $\mathrm{CD} 86^{+} \mathrm{CD} 27^{-} \mathrm{B}$ cells were similar in patients who flared recently and those who did not (Supplemental Figure 9B). Other endpoints (\% of DN B cells, \% of CD $86^{+} \mathrm{CD} 27^{+} \mathrm{B}$ cells, $\%$ of $\mathrm{CD} 4{ }^{10} \mathrm{CD} 27^{-}$and $\mathrm{CD} 27^{+} \mathrm{B}$ cells, \% of CD $40 \mathrm{~L}^{+} \mathrm{CD} 27^{-} \mathrm{B}$ cells) showed similar results (data not shown). We also ruled out the possibility that active LN could drive this phenotype, as only 2 of 14 African American and 1 of 15 European American LN patients had active nephritis; other LN patients had inactive nephritis. Therefore, it is unlikely that the activated B cell phenotype that is more pronounced in African American patients is a consequence of recent or current disease activity. Finally, as we were confident that the enrichment of B cells with an activated phenotype in African American patients was not due to other confounding factors, we tested whether B cells from African American SLE patients were more responsive to CD40L stimulation ex vivo. An overnight stimulation of whole blood B cells with CD40L-IZ revealed a similar upregulation of CD86 surface expression in NHV and SLE patients, as well as in African American and European American SLE patients (Supplemental Figure 10). We could therefore not show an intrinsic propensity of African American SLE B cells to respond differently to stimulation through the CD40 pathway.

Patients with higher $C D 40^{\circ} \mathrm{CD} 27^{-} \mathrm{B}$ cell frequencies also have increased anti-Sm, anti-Sm/RNP, and anti-dsDNA autoantibody titers. The secretion of autoantibodies is a hallmark of SLE. By forming immune complexes with autoantigens, autoantibodies have a direct pathogenic role on tissues and organs, and they activate innate and adaptive immune cells. In fact, the presence of autoantibodies, such as anti-dsDNA antibodies, has been associated with flares $(6,25)$. Therefore, we analyzed antibody titers in African American patients versus patients of European descent. There was an increase of anti-Sm/RNP and anti-RNP70 titers in African American SLE patients compared with European American patients (Supplemental Figure 11). Anti-Sm autoantibodies were also increased in African American patients, compared with patients of 
European descent, but the difference did not reach statistical significance (Supplemental Figure 11). We then inquired whether patients with higher frequencies of $C D 40^{\text {lo }} \mathrm{B}$ cells also had higher titers of autoantibodies, analyzing European American and African American patients separately. African American SLE patients with $\mathrm{CD} 40^{\text {lo }} \mathrm{CD} 27^{-} \mathrm{B}$ cell frequencies higher than $1.54 \%$, which corresponds to the $90^{\text {th }}$ percentile of $\mathrm{CD} 40^{\mathrm{lo}} \mathrm{CD} 27^{-} \mathrm{B}$ cell frequencies in NHV, had significantly higher anti-Sm/RNP, anti-Sm, and anti-dsDNA IgG plasma levels. In addition, European American patients with higher anti-Sm/RNP, anti-Sm, and antidsDNA titers also had higher frequencies of $\mathrm{CD} 40^{\mathrm{lo}} \mathrm{CD} 27^{-} \mathrm{B}$ cells, the difference reaching significance for anti-Sm titers (Figure 8). These results support the hypothesis that the particular B cell phenotype observed in SLE African American patients reflects an increased activation of B cells, possibly via the CD40 pathway.

\section{Discussion}

To the best of our knowledge, this report is the first to describe in detail an immune phenotype overly represented in African American SLE patients. Previous studies have shown a differential phenotype in African American patients but were focused on mRNA expression analysis (26) or soluble factors (27). In our cohort of SLE patients with low to moderate disease activity, patients with African ancestry have increased frequencies of DN B cells and an activated B cell phenotype - as defined by the higher expression of CD86, CD80, PD1, and CD40L - and lower expression of CD40 compared with patients of European descent. Although we could not directly demonstrate internalization of CD40 in SLE patients, the lower level of surface expression of CD40 combined with the increased expression of CD40L in the same patients and the in vitro evidence that CD40L can induce CD40 by internalization suggests that CD $40^{\text {lo }} \mathrm{B}$ cells could likely be cells in which the CD40 pathway is engaged.

CD40-CD40L interactions are crucial for B cell proliferation, survival, activation, and isotype switching. In fact, CD40L or CD40 deficiencies lead to hyper-IgM syndromes, characterized by the absence of germinal centers and IgG and IgA antibodies (28). In addition, the blockade of CD40L in mice results in aborted germinal center reactions (29). CD40L is upregulated on activated T cells (11), which can deliver help to B cells via CD40-CD40L interactions. In the context of SLE, B cells can also express CD40L (12, 13). Not only did we find an increase in CD40L-expressing B cells in SLE patients compared with NHV, but we also showed that this increase was particularly pronounced in SLE African American patients. In addition, we demonstrated that CD40 signaling leads to upregulation of CD40L expression by B cells in vitro. CD40L expressed by B cells could induce B cell activation via engagement of CD40 (15). We found that the same patients who had increased CD40L expression on B cells had decreased surface CD40 expression on a subset of their B cells, suggesting B cell-B cell interactions leading to CD40 pathway engagement. Consistent with this hypothesis, we demonstrated that both soluble CD40L and membrane-bound CD40L, including CD40L expressed on the surface of B cells, could induce CD40 internalization and subsequent B cell activation. We could therefore speculate that CD40L expressed by B cells in African American SLE

Table 2. African American ancestry is the strongest predictor for the activated B cell phenotype of SLE patients

\begin{tabular}{|c|c|c|c|}
\hline Endpoints & variable & $\log (\beta$ Coefficient) & $P$ value \\
\hline \multirow[t]{2}{*}{$\%$ DN B cells } & Ancestry (Afr. Am.) & 1.133 & $2.24 \times 10^{-5}$ \\
\hline & Total count of ACR criteria & 0.344 & 0.0018 \\
\hline \multirow[t]{4}{*}{$\% \mathrm{CD}^{\circ} 6^{+} \mathrm{CD}^{2} 7^{-} \mathrm{B}$ cells } & Ancestry (Afr. Am.) & 1.133 & $6.29 \times 10^{-5}$ \\
\hline & Glucocorticoids & 0.817 & 0.00987 \\
\hline & Duration of disease & -0.0275 & 0.0126 \\
\hline & Low complement & 0.315 & 0.0181 \\
\hline \multirow[t]{2}{*}{$\% \mathrm{CD}^{\circ} 6^{+} \mathrm{CD} 27^{+} \mathrm{B}$ cells } & Ancestry (Afr. Am.) & 0.495 & 0.00623 \\
\hline & Glucocorticoids & 0.373 & 0.0387 \\
\hline$\%$ CD40 ${ }^{\circ} \mathrm{CD} 27^{-} \mathrm{B}$ cells & Ancestry (Afr. Am.) & 1.455 & 0.00079 \\
\hline$\%$ CD40 ${ }^{\circ} \mathrm{CD} 27^{+} \mathrm{B}$ cells & Ancestry (Afr. Am.) & 0.411 & 0.0129 \\
\hline \multirow[t]{2}{*}{$\%$ CD4OL + CD27- $^{-}$B cells } & Ancestry (Afr. Am.) & 1.42 & $5.93 \times 10^{-6}$ \\
\hline & Ancestry (Afr. Am.):Discoid rash & -1.064 & 0.0263 \\
\hline
\end{tabular}

Multiple linear regression analysis was used to evaluate the association for each of 6 indicated response endpoints and 15 demographic and clinical endpoints as covariates. Only covariates displaying statistical significance $(P$ value $<0.05)$ are shown. Afr. Am., African American 
A
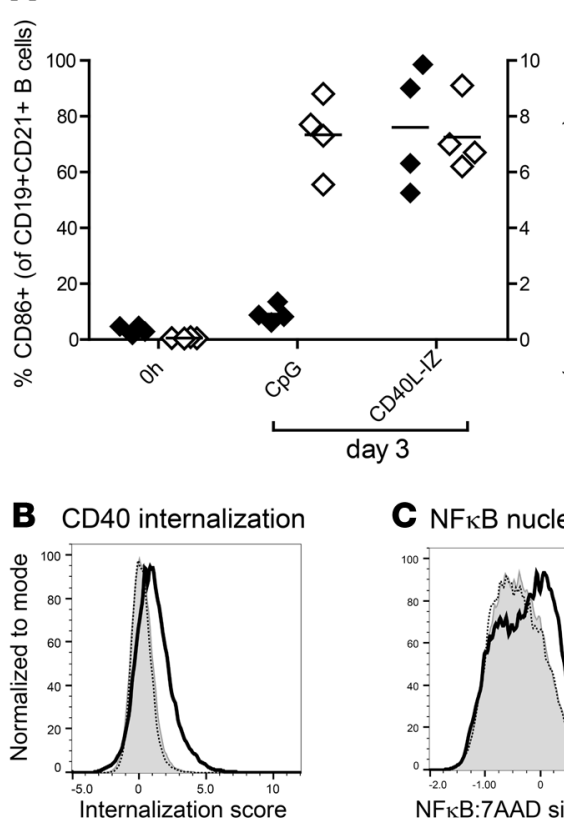

C NFKB nuclear translocation
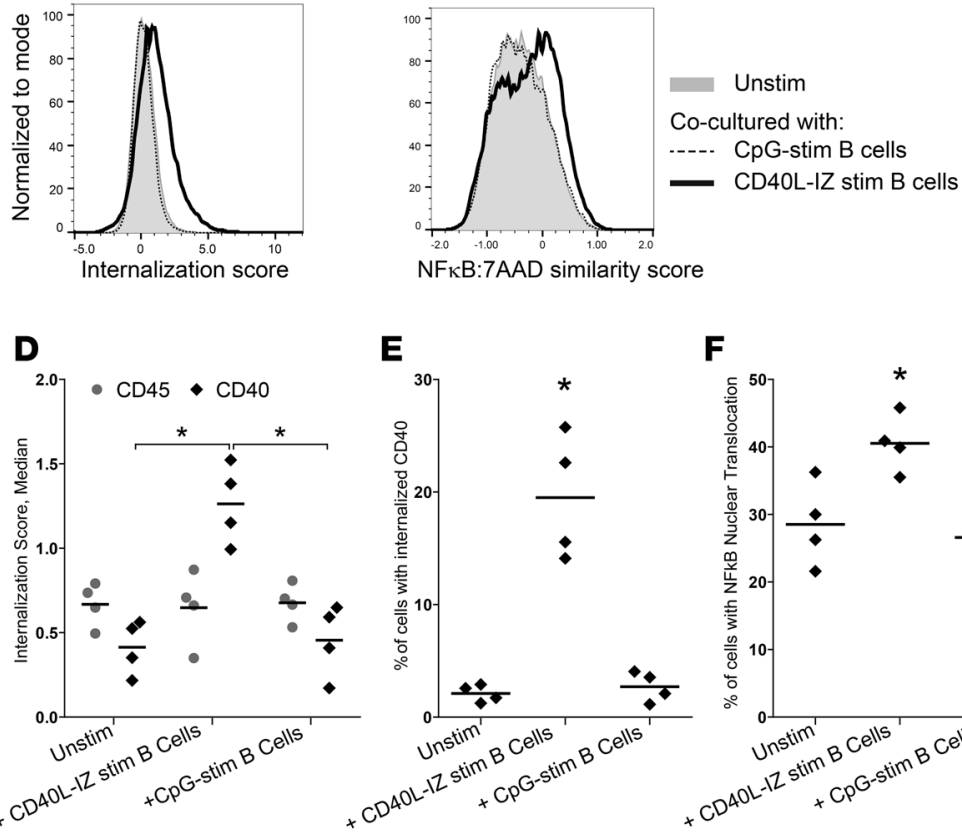

E
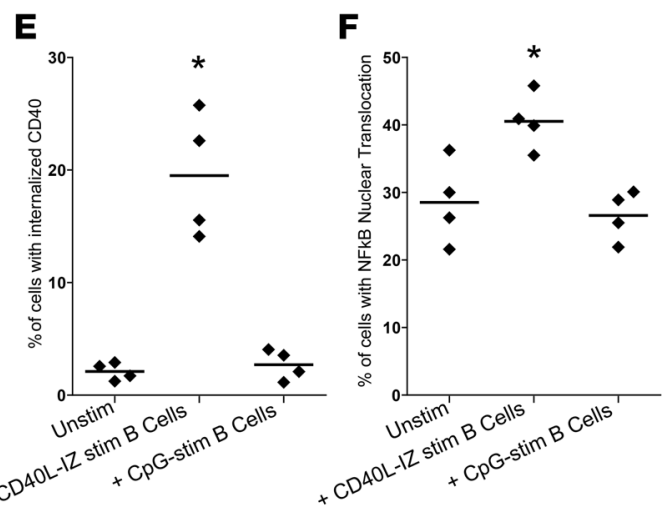

Figure 6. B cell expression of CD40 ligand (CD4OL) can induce CD40 internalization and pathway activation in trans. (A) CD86 and CD4OL expression in freshly isolated CD19+ $B$ cells and after 3 days of culture with $C p G$ oligodeoxynucleotides (CpG) or soluble CD40L-isoleucine zipper (CD4OL-IZ). (B-F) Internalization of CD40 (B) and NF- $\mathrm{BB}$ nuclear translocation (NF- $\mathrm{KB}$ :7-aminoactinomycin $\mathrm{D}$ [7-AAD] similarity score) (C) on B cells freshly isolated (Unstim) or cocultured for 1 hour with autologous B cells previously stimulated for 3 days with CD4OL-IZ (CD4OL-IZ stim B cells) or CpG (CpG-stim B cells). Quantification of CD40 (black) and CD45 (gray) internalization by median internalization score (D), percentage of cells with CD40 internalization score $>2.5$ (E), or percentage of cells with NF-KB translocation (NF- $\mathrm{kB}$ :7-AAD similarity score $>0$ ) (F) on B cells stimulated in indicated conditions. Averaged results from 2 donors from 4 different experiments are represented on the graphs (D-F). ${ }^{*} P<0.05$ by Mann-Whitney test. Purified total B cells from normal healthy volunteers were used.

patients could induce internalization and activation of CD40 on B cells, leading to upregulation of CD86 and $\mathrm{CD} 40 \mathrm{~L}$ and differentiation into antibody-secreting cells. In fact, in mice where CD40 signaling on B cells could only be provided by CD40L constitutively expressed by B cells, there was an increased early output of plasma cells from germinal centers (30). Moreover, mice with constitutive CD40L expression spontaneously develop lupus (31). Tipton et al. described in SLE patients a population of activated naive B cells contributing to the pool of antibody-secreting cells, potentially through both germinal center reactions and extrafollicular pathways (32).

Could the activation of naive $B$ cells via the $C D 40$ pathway explain the expanded DN B cell compartment? DN IgD- $\mathrm{CD}^{-} 7^{-} \mathrm{B}$ cells are a poorly understood subset of memory cells with mutated B cell receptor

(BCR). They can be $\mathrm{IgM}^{+}, \mathrm{IgG}^{+}$, or $\mathrm{IgA}^{+}$and share morphology and clones with regular $\mathrm{CD}^{2} 7^{+} \mathrm{IgM}^{+}$, $\mathrm{IgG}^{+}$, and IgA+ memory B cells, respectively (33-36), suggesting a common lineage. Whether DN B cells are precursors for $\mathrm{CD} 27^{+}$memory B cells or have lost $\mathrm{CD} 27$ expression is unknown. Strikingly, in our study, the same patients of African ancestral background who have increased DN B cell frequencies have an increased activated B cells phenotype. It might suggest that activation of naive B cells, possibly in a $\mathrm{T}$ cell-independent pathway through CD40L expressed by B cells, leads to the formation of this DN B cell compartment. In the context of autoimmunity, DN B cells are enriched in SLE patients and accumulate in the inflamed joints of children with juvenile idiopathic arthritis $(23,33,37)$, suggesting that these cells may be generated at the site of inflammation and recirculation. Several groups have suggested that DN B cells could constitute a reservoir of autoreactive B cells, possibly anergic (34). In fact, we have no evidence that DN B cells are contributing to the production of autoantibodies. Both increased autoantibody titers and DN B cell frequencies could be the consequences of the same cause: the activation of naive autoreactive $B$ cells via CD40. The SLE naive B cell pool contains higher frequencies of polyreactive and autoreactive cells (38). A T cell-independent activation of these naive B cells via CD40, possibly in combination with $B C R$ or TLR9 stimulation, could lead to production of autoantibodies as well as anergy as an attempt by the immune system to control autoimmunity (39). This scenario does not exclude the possibility that activation of the CD40 pathway could also rescue autoreactive (DN) B cells from their anergic state (40), leading to autoantibody production. Finally, another possibility could be that increased plasma levels of B cell activating factor (BAFF) in African American SLE patients compared with European American patients (27) (Supplemental Figure 12) result in a more activated B cell phenotype, as well as higher frequencies of DN 
A

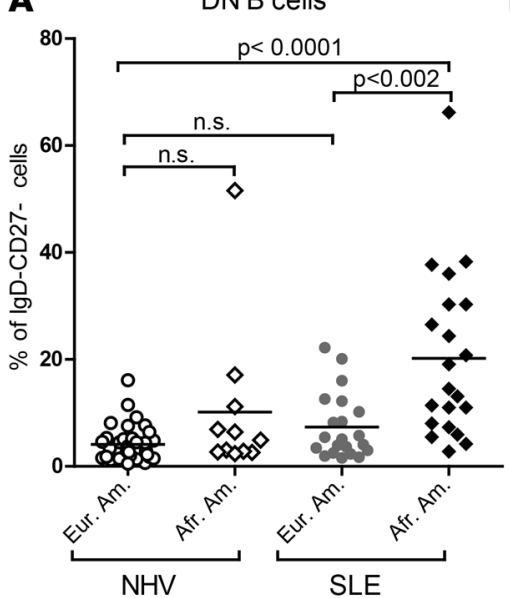

C Unswitched memory B cells

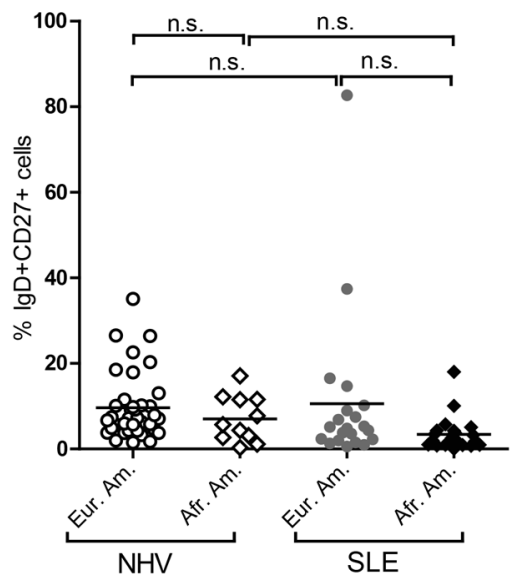

B

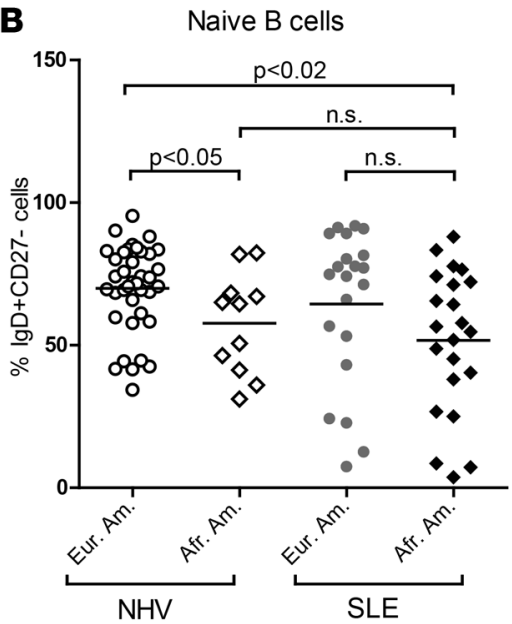

D

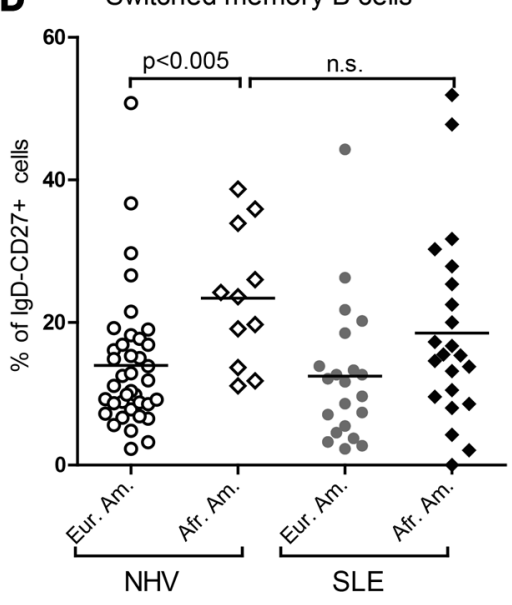

Figure 7. Increased frequency of double-negative (DN) B cells in African American (Afr. Am.) systemic lupus erythematosus (SLE) patients. Frequencies of $C D 19^{+} \mid g D-C D 27-D N B$

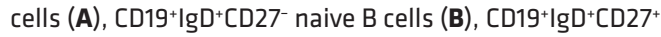
unswitched memory B cells (C), and CD19+'IgD-CD27+ switched B cells (D) in whole blood of 38 European American (Eur. Am.) and $11 \mathrm{Afr}$. Am. normal healthy volunteer (NHV) donors and 21 Eur. Am. and $21 \mathrm{Afr}$. Am. SLE patients. The horizontal bars represent the average for each group. $P$ values are indicated (Mann-Whitney test).

B cells in African American patients, since the maintenance of DN B cells appears to require BAFF (41).

What could initiate this CD40/CD40L feed-forward loop in B cells from African American patients? Disease activity scores, comorbidities, and medications were similar in both ancestries, and we did not identify other confounding factors; African American ancestry was the strongest predictor of the singular B cell phenotype described in this report, independent of flare or LN history. Ancestries were self-reported, and we were not provided with family history for confirmation. Therefore, it is very likely that different degrees of admixture could lead to some heterogeneity within these 2 groups of patients. Nevertheless, differences in genetic backgrounds could potentially explain the differences in CD40/CD40L pathway activation. GWAS studies have identified several polymorphisms that alter the risk of developing SLE. Unfortunately, most of these studies have been conducted on individuals of European ancestry. Few risk alleles specific to African American SLE patients have been identified. The SNP rs5029953 in the TNFAIP3 locus is essentially represented in the African American population and confers an increased risk of SLE (42). TNFAIP3 codes for A20, which is a negative regulator of NF- $\mathrm{B}$ signaling downstream of CD40 in B cells. In mice, B cells lacking A20 had an increase response to activation with different stimuli, including anti-CD40 (43). Polymorphisms in the CD40 locus in Chinese, Turkish, and Greek populations have been linked to SLE $(44,45)$, but it is unknown if these SNPs confer any altered risk of SLE to African American individuals. In fact, we could not find any evidence in our cohort of an intrinsic propensity of B cells from African American patients to respond differently to CD40L stimulation. However, this result does not rule out subtle differences in timing of response or sensitivity to stimulus. Extrinsic factors could also initiate the CD40-CD40L feed-forward activation loop in B cells. We found a small increase of CD40L expression in naive CD4 ${ }^{+}$and $\mathrm{CD} 8^{+} \mathrm{T}$ cells in African American compared with European American SLE patients. It did not correlate with frequencies of CD40 ${ }^{\text {lo }} \mathrm{B}$ cells; thus, $\mathrm{T}$ cells may not play as much of a role as B cells in the maintenance of the CD40/ CD40L feed-forward loop. However CD40L expressed by $\mathrm{T}$ cells may participate in the triggering of this activating loop, as could CD40L expressed by other cells, such as monocytes (46). Alternatively, cytokines such as IL-2 and IL-4, in combination with BCR stimulation, could drive the upregulation of CD40L on B cells and initiate the CD40/CD40L feed-forward loop (15).

In conclusion, we showed that, in our cohort, African American SLE patients - compared with European American patients with similar disease activity - displayed a significant enrichment in a particular B cell phenotype with upregulation of activation markers and downregulation of CD40 surface expression. By performing in vitro experiments, we showed that activation of the CD40 pathway on B cells can lead to upregulation of CD40L surface expression, which could, in turn, engage CD40 expressed by B cells in a feed-forward loop. These findings could at least partially explain the tendency of African American patients to progress to a more severe disease with higher risk of flaring and progression to kidney disease. They 

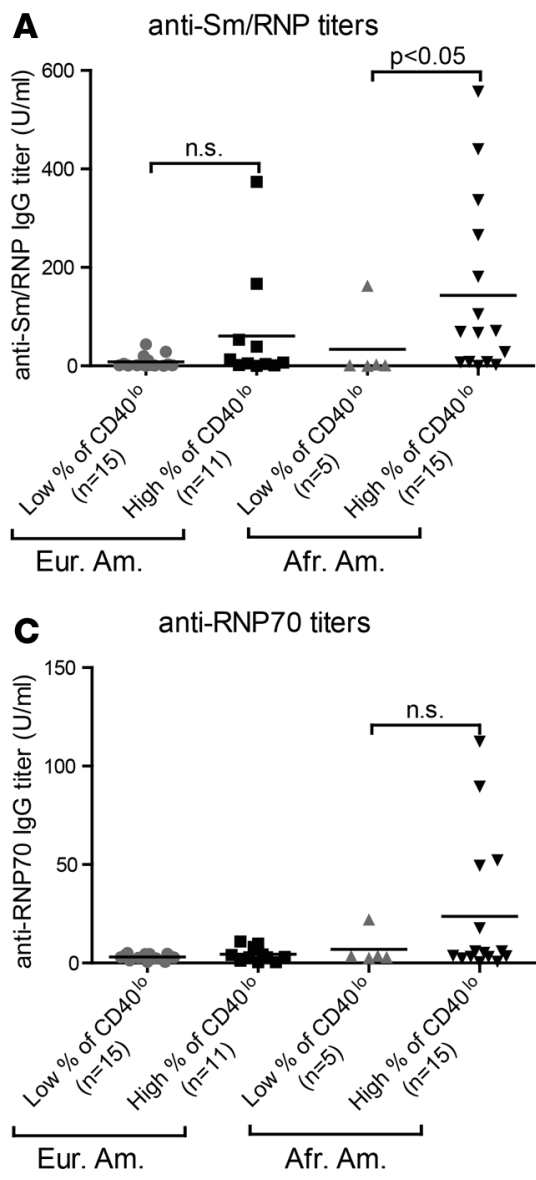
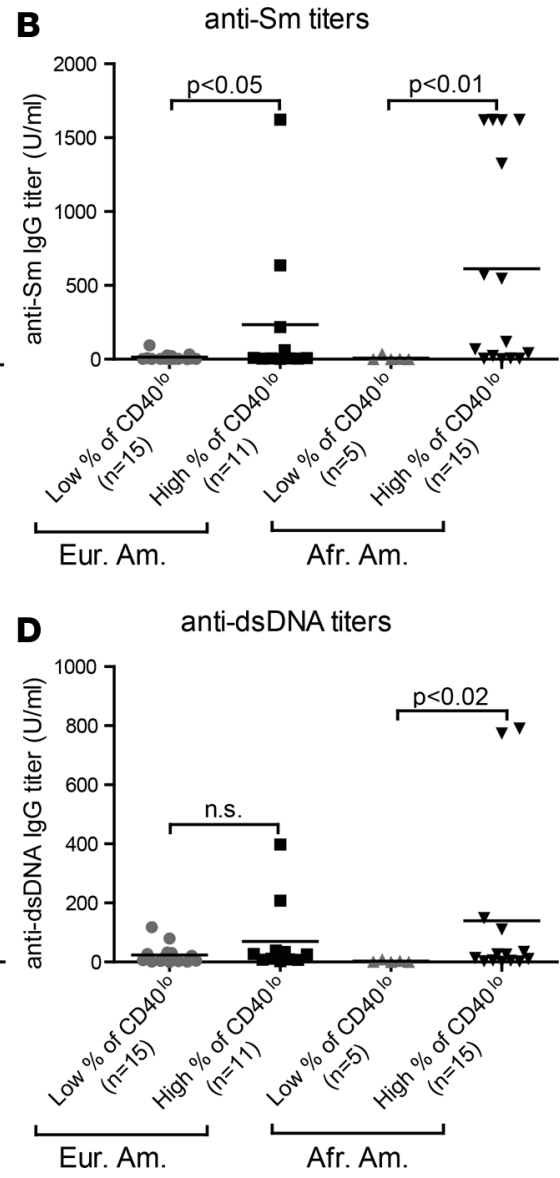

Figure 8. Higher frequencies of $\mathrm{CD} 40^{10} \mathrm{CD} 27^{-} \mathrm{B}$ cells correlate with higher titers of autoantibodies. AntiSmith/ribonucleoprotein (Sm/RNP) (A), anti-Sm (B), anti-RNP7O (C), and anti-dsDNA (D) IgC plasma levels in 15 European American (Eur. Am.) and 5 African American (Afr. Am.) systemic lupus erythematosus (SLE) patients with low frequencies of $C D 40^{\circ}{ }^{\circ} \mathrm{CD} 27^{-} \mathrm{B}$ cells and 11 Eur. Am. and 15 Afr. Am. SLE patients with high frequencies of $C D 40^{\circ} \mathrm{CD} 27^{-} B$ cells (cutoff was set at $1.54 \%$ of $\mathrm{CD} 4 \mathrm{O}^{\mathrm{l}} \mathrm{CD} 27^{-} \mathrm{B}$ cells, which corresponds to the 90th percentile in normal healthy volunteer [NHV] donors). $P$ value for statistically significant differences are indicated (Mann-Whitney). The horizontal bar represents the average for each group.

also suggest that African American patients may benefit more from therapies targeting $\mathrm{B}$ cells or aimed at specifically blocking the CD40/CD40L pathway - hypotheses that will only be confirmed by performing clinical trials that include patients of diverse ancestral backgrounds.

\section{Methods}

Patients. We obtained peripheral blood in 2014 and 2015 from 68 SLE patients (29 patients self-identified as "Black or African American" and 39 patients of European ancestry self-identified as "Caucasian") who were visiting their physician at Northwell Health, Great Neck, New York, USA. Most patients were on standard-of-care treatment for general SLE. Details of medication and asso-

ciated comorbidities are summarized in Table 1. Healthy subjects were analyzed in parallel (Supplemental Table 3). Blood was shipped overnight. Immediately upon reception, plasma was collected and frozen for further use, and peripheral blood mononuclear cells (PBMC) were purified.

Flow cytometry. Heparin anticoagulated blood ( $80 \mu 1)$ or 1 million freshly isolated PBMC were incubated with premixed cocktails of conjugated antibodies. Antibodies used for whole blood were: CD3-eFluor 450 or CD3-Alexa Fluor700 (AF700) (both clone OKT3), CD45RA-fluorescein isothiocyanate (FITC) (clone JS-83), CD27-allophycocyanin (APC) (clone O323), IgD-FITC (clone IA6-2), CD24-phycoerythrin (PE) (clone SN3 A5-2H10), and CD38-peridinin-Chlorophyll-protein(PerCP)-eFluor710 (clone HB7) (all eBiosciences); CD4-PE-cyanine7 (Cy7) (clone OKT4), CXCR3-AF647 (clone G025H7), CCR6-Brilliant violet 785 (BV785) (clone G034E3), PD1-BV605 (clone EH12.2H7), and CD19-BV421 (clone HIB19) (all BioLegend); and CD8a-APC-H7 (clone SK1), CCR7-PE-CF594 (clone 150503), CXCR5-BV510 (clone RF8B2), and CD20-APC-H7 (clone 2H7) (all BD Biosciences). For PBMC: CD3-APC-eFluor 780 (clone UCHT1), CD4-PerCPCy5.5 (clone RPA-T4), CD8a-PECy7 (clone RPA-T8), and PD1-PerCPCy5.5 (clone EH12.2H7) (all eBiosciences); CD19-APC-Cy7 (clone HIB19), CD40-PE (clone 5C3), CD40L-PE (clone 24-31), CD80-FITC (clone 2D10), CD86-APC (clone IT2.2), and CD45RO-Pacific Blue (clone UCHL1) (all BioLegend); and CD27-BV605 (clone L128) (BD Biosciences). Whole blood samples were lysed for red blood cells and fixed with FACS lysing buffer. Stained PBMC samples were fixed in $1.5 \%$ paraformaldehyde. Samples were run on LSR-Fortessa or LSRII (BD Biosciences) and analyzed with FlowJo V10.0.7. Exclusion of doublets was systematically applied in the gating strategy (Supplemental Figure 6).

Upregulation of surface markers during in vitro B cell activation. Total B cells were purified from freshly isolated PBMC by magnetic negative selection as described by the manufacturer (StemCell Technologies). Cells (250,000/well) were cultured in RPMI supplemented with antibiotics and 10\% FBS without or with $1 \mu \mathrm{g} / \mathrm{ml}$ of hCD40L-IZ (47), $20 \mu \mathrm{g} / \mathrm{ml}$ of goat anti-human IgM F(ab') (Jackson ImmunoResearch), and $1 \mu \mathrm{g} / \mathrm{ml}$ of $\mathrm{CpG}$ ODN2006-B (Invivogen) or cocultured with 25,000 CHO cells stably transfected with human CD40LG (hCD40L-CHO cells) at Bristol-Myers Squibb. Parental CHO DG44 cells were obtained 
from Lawrence Chasin (Columbia University, New York, New York, USA). At indicated timepoints, cells were collected, washed, and stained with CD19-APC-Cy7 (clone HIB19, BioLegend), CD27-BV605 (clone L128, BD Biosciences), CD80-FITC (clone 2D10, BioLegend), CD86-APC (clone IT2.2, BioLegend), CD40-PE (clone 5C3, BioLegend), CD40L-PE (clone 24-31, BioLegend), and PD1-PerCPCy5.5 (clone $\mathrm{EH} 12.2 \mathrm{H} 7$, eBiosciences); fixed in 1\% paraformaldehyde; and run on LSRII (BD Biosciences). Samples were analyzed with FlowJo V10.0.7.

To compare the response to CD40L stimulation by B cells from different ancestral backgrounds, CD40L-driven upregulation was tested in a whole blood assay. Heparin anticoagulated blood (90 $\mu 1$; SLE and NHV) was rested for 1 hour before addition of $10 \mu \mathrm{g} / \mathrm{ml}$ of CD40L-IZ. After an overnight incubation, samples were stained with CD20-APC and CD86-PE (eBiosciences) and run on Canto II (BD Biosciences).

$C D 40$ receptor internalization and $N F-\kappa B$ nuclear translocation. Total B cells were isolated from frozen PBMCs by magnetic negative selection as described by the manufacturer (StemCell Technologies). Freshly isolated B cells were stained for 30 minutes on ice with anti-CD40-PE (clone 5C3, BioLegend) and with anti-CD45-APC/Cy7 (clone H130, BioLegend) in Stain Buffer (BSA) (BD Biosciences) containing $\mathrm{Hu}$ FcR Binding Inhibitor (eBioscience). After staining, B cells $\left(3.0 \times 10^{6}\right.$ cells/well in 12 -well plate) were incubated for 1 hour at $37^{\circ} \mathrm{C}\left(5 \% \mathrm{CO}_{2}\right)$ in RPMI 1640 supplemented with heat-inactivated $10 \% \mathrm{FBS}, 1 \%$ penicillin-streptomycin, and $1 \%$ L-glutamine in the presence or absence of $1 \mu \mathrm{g} / \mathrm{ml}$ CD40L-IZ, hCD40L-CHO cells (1:10 hCD40L-CHO:B cell ratio), or autologous B cells previously activated for 72 hours at $37^{\circ} \mathrm{C}\left(5 \% \mathrm{CO}_{2}\right)$ in RPMI with $1 \mu \mathrm{g} / \mathrm{ml}$ CD40L-IZ or $1 \mu \mathrm{g} / \mathrm{ml}$ CpG ODN2006-B (Invivogen) (1:1 ratio). B cell stimulation was stopped by incubating cells on ice for 10 minutes. Cells were washed and stained on ice in BD Stain Buffer with CD19-BV510 (clone H1B19, BioLegend). After fixation in 4\% paraformaldehyde (PFA) (Alfa Aesar), cells were permeabilized for 20 minutes at $4^{\circ} \mathrm{C}$ in $1 \times$ BD Perm/Wash buffer (BD Biosciences). Permeabilized cells were then stained on ice in Perm/Wash buffer with anti-NF-кB p50-AF488 (clone 4D1, BioLegend), washed in Perm/Wash buffer, and then fixed again. A nuclear staining dye, 7-AAD Viability Staining Solution (BioLegend), was added to all samples 10 minutes prior to data acquisition.

ImageStream data acquisition and analysis. ImageStream data acquisition and analysis were performed as previously described $(19,20)$. Data acquisition was done using Amnis ImageStream ${ }^{\mathrm{X}}$ Mark II imaging flow cytometer (EMD Millipore) and INSPIRE acquisition software (EMD Millipore). Collected images were analyzed using IDEAS V.6.2 image-analysis software (Amnis, EMD Millipore). In each sample, 60,000 events were collected and imaged in the extended depth of field mode (EDF). Digital spectral compensation was performed on a pixel-by-pixel basis using single-stained controls. Acquired cellular imagery was analyzed for the degree of CD40 and CD45 internalization using the internalization feature (19) and for the degree of NF- $\mathrm{kB}$ p50 nuclear translocation using the similarity feature (20), as described in IDEAS V.6.2 documentation.

ELISA. Levels of sCD40L and BAFF in plasma were detected with human CD40L and human BAFF ELISA kits, respectively (both R\&D Systems), following the manufacturer's instructions. For autoantibody titers, plasma samples were diluted 100-fold into sample dilution buffer and incubated on a precoated plate with dsDNA (ALPCO), Sm (ALPCO), Sm/RNP (ALPCO), or RNP70 (Genway Biotech). ELISA was developed with horseradish peroxidase-conjugated anti-human IgG followed by TMB substrate. The reaction was stopped with $1 \mathrm{M}$ hydrochloric acid and read on a dual-wavelength spectrophotometer. Values were calculated based on the standard curve and were reported as IU/ml.

Statistics. Descriptive and single-factor statistical analyses were performed with GraphPad Prism 5. Mann-Whitney nonparametric $t$ test was used to compare groups. $P$ values were adjusted to correct for multiple comparisons and repeated measures. The following formula was used: adjusted $P=1-(1-\alpha)^{\mathrm{k}}$, where $\alpha$ is the nonadjusted $P$ value and $\mathrm{k}$ is the number of comparisons. k was set at 30 . Correlations were analyzed with Spearman correlation. A $P$ value of 0.05 or lower was considered significant.

Multiple linear regression analysis was performed in $\mathrm{R}$ statistical package. To ensure normality, log transformation was used for all 6 tested endpoints as response variables (\% of CD86 ${ }^{+}$in $\mathrm{CD}_{27}$ and $\mathrm{CD} 27^{+} \mathrm{B}$ cells, $\%$ of $\mathrm{CD} 40^{\mathrm{lo}} \mathrm{CD} 27^{-}$and $\mathrm{CD} 27^{+} \mathrm{B}$ cells, $\%$ of $\mathrm{CD} 40 \mathrm{~L}^{+} \mathrm{CD} 27^{-} \mathrm{B}$ cells, $\%$ of DN B cells). The covariates tested as predictor variables were: age, sex, self-reported African American ancestry, duration of disease, SLEDAI-2k, total count of ACR criteria and some of its components (renal disorder, discoid rash, malar rash, and arthritis), the presence of nephritis, and low complement and treatment with hydroxychloroquine, mycophenolate mofetil, and glucocorticoids. The presence of the comorbidities idiopathic thrombocytopenic purpura (ITP), Sjogren's syndrome, and antiphospholipid syndrome and the effect of belimumab 
were not tested because of the paucity of samples being positive for these variables. A variable selection procedure based on Akaike's information criterion was used to select informative predictor variables.

Study approval. All samples were collected in accordance with Northwell Health IRB or Bristol-Myers Squibb institutional biosafety committee-reviewed protocols. Written informed consent was obtained from participants prior to inclusion in the study.

\section{Author contributions}

LCM, SH, WG, DL, DB, DAH, FC, PMD, and SK performed experiments and analyzed data. CKZ performed the multivariate analysis. NMO, MC, and DS helped with experiments and data analysis. FA and $\mathrm{RF}$ recruited patients, collected all clinical annotations, and provided intellectual input. LCM wrote the manuscript. JC, SGN, and SJS provided intellectual input and helped preparing the manuscript.

Address correspondence to: Laurence Menard, Discovery Translational Sciences, Bristol-Myers Squibb Company, Route 206 and Province Line Rd, Princeton, New Jersey 08540, USA. Phone: 609.252.7244; E-mail: Laurence.menard@bms.com.

1. Mohan C, Putterman C. Genetics and pathogenesis of systemic lupus erythematosus and lupus nephritis. Nat Rev Nephrol. 2015;11(6):329-341.

2. Jacobi AM, et al. Correlation between circulating CD2 $7^{\text {high }}$ plasma cells and disease activity in patients with systemic lupus erythematosus. Arthritis Rheum. 2003;48(5):1332-1342.

3. Gonzalez LA, Toloza SM, McGwin G Jr., Alarcon GS. Ethnicity in systemic lupus erythematosus (SLE): its influence on susceptibility and outcomes. Lupus. 2013;22(12):1214-1224.

4. Sule S, Fivush B, Neu A, Furth S. Increased risk of death in African American patients with end-stage renal disease secondary to lupus. Clin Kidney J. 2014;7(1):40-44.

5. Nee R, et al. Survival disparity of African American versus non-African American patients with ESRD due to SLE. Am J Kidney Dis. 2015;66(4):630-637.

6. Petri M, Singh S, Tesfasyone H, Malik A. Prevalence of flare and influence of demographic and serologic factors on flare risk in systemic lupus erythematosus: a prospective study. J Rheumatol. 2009;36(11):2476-2480.

7. Merrill JT, et al. Efficacy and safety of rituximab in moderately-to-severely active systemic lupus erythematosus: the randomized, double-blind, phase II/III systemic lupus erythematosus evaluation of rituximab trial. Arthritis Rheum. 2010;62(1):222-233.

8. Rovin BH, et al. Efficacy and safety of rituximab in patients with active proliferative lupus nephritis: the Lupus Nephritis Assessment with Rituximab study. Arthritis Rheum. 2012;64(4):1215-1226.

9. Bij1 M, Horst G, Limburg PC, Kallenberg CG. Expression of costimulatory molecules on peripheral blood lymphocytes of patients with systemic lupus erythematosus. Ann Rheum Dis. 2001;60(5):523-526.

10. Agata Y, et al. Expression of the PD-1 antigen on the surface of stimulated mouse T and B lymphocytes. Int Immunol. 1996;8(5):765-772.

11. Koshy M, Berger D, Crow MK. Increased expression of CD40 ligand on systemic lupus erythematosus lymphocytes. J Clin Invest. 1996;98(3):826-837.

12. Desai-Mehta A, Lu L, Ramsey-Goldman R, Datta SK. Hyperexpression of CD40 ligand by B and T cells in human lupus and its role in pathogenic autoantibody production. J Clin Invest. 1996;97(9):2063-2073.

13. Manea ME, et al. Increased expression of CD154 and FAS in SLE patients' lymphocytes. Rheumatol Int. 2009;30(2):181-185.

14. Vakkalanka RK, Woo C, Kirou KA, Koshy M, Berger D, Crow MK. Elevated levels and functional capacity of soluble CD40 ligand in systemic lupus erythematosus sera. Arthritis Rheum. 1999;42(5):871-881.

15. Grammer AC, Bergman MC, Miura Y, Fujita K, Davis LS, Lipsky PE. The CD40 ligand expressed by human B cells costimulates B cell responses. J Immunol. 1995;154(10):4996-5010.

16. Manning E, Pullen SS, Souza DJ, Kehry M, Noelle RJ. Cellular responses to murine CD40 in a mouse B cell line may be TRAF dependent or independent. Eur J Immunol. 2002;32(1):39-49.

17. Hostager BS, Catlett IM, Bishop GA. Recruitment of CD40 and tumor necrosis factor receptor-associated factors 2 and 3 to membrane microdomains during CD40 signaling. J Biol Chem. 2000;275(20):15392-15398.

18. Wang HM, et al. Scaffold protein JLP is critical for CD40 signaling in B lymphocytes. J Biol Chem. 2015;290(9):5256-5266.

19. Vallhov H, et al. Exosomes containing glycoprotein 350 released by EBV-transformed B cells selectively target B cells through CD21 and block EBV infection in vitro. J Immunol. 2011;186(1):73-82.

20. George TC, et al. Quantitative measurement of nuclear translocation events using similarity analysis of multispectral cellular images obtained in flow. J Immunol Methods. 2006;311(1-2):117-129.

21. Simpson N, et al. Expansion of circulating T cells resembling follicular helper T cells is a fixed phenotype that identifies a subset of severe systemic lupus erythematosus. Arthritis Rheum. 2010;62(1):234-244.

22. Choi JY, et al. Circulating follicular helper-like T cells in systemic lupus erythematosus: association with disease activity. Arthritis Rheumatol. 2015;67(4):988-999.

23. Huang W, et al. The effect of anti-CD40 ligand antibody on B cells in human systemic lupus erythematosus. Arthritis Rheum. 2002;46(6):1554-1562.

24. Jabara HH, Brodeur SR, Geha RS. Glucocorticoids upregulate CD40 ligand expression and induce CD40L-dependent immunoglobulin isotype switching. J Clin Invest. 2001;107(3):371-378. 
25. Petri MA, et al. Baseline predictors of systemic lupus erythematosus flares: data from the combined placebo groups in the phase III belimumab trials. Arthritis Rheum. 2013;65(8):2143-2153.

26. Sharma S, Jin Z, Rosenzweig E, Rao S, Ko K, Niewold TB. Widely divergent transcriptional patterns between SLE patients of different ancestral backgrounds in sorted immune cell populations. J Autoimmun. 2015;60:51-58.

27. Ritterhouse LL, et al. B lymphocyte stimulator levels in systemic lupus erythematosus: higher circulating levels in African American patients and increased production after influenza vaccination in patients with low baseline levels. Arthritis Rheum. 2011;63(12):3931-3941.

28. Qamar N, Fuleihan RL. The hyper IgM syndromes. Clin Rev Allergy Immunol. 2014;46(2):120-130.

29. Han S, Hathcock K, Zheng B, Kepler TB, Hodes R, Kelsoe G. Cellular interaction in germinal centers. Roles of CD40 ligand and B7-2 in established germinal centers. J Immunol. 1995;155(2):556-567.

30. Bolduc A, et al. Constitutive CD40L expression on B cells prematurely terminates germinal center response and leads to augmented plasma cell production in T cell areas. J Immunol. 2010;185(1):220-230.

31. Higuchi T, et al. Cutting Edge: Ectopic expression of CD40 ligand on B cells induces lupus-like autoimmune disease. J Immunol. 2002;168(1):9-12

32. Tipton CM, et al. Diversity, cellular origin and autoreactivity of antibody-secreting cell population expansions in acute systemic lupus erythematosus. Nat Immunol. 2015;16(7):755-765.

33. Wei C, et al. A new population of cells lacking expression of CD27 represents a notable component of the B cell memory compartment in systemic lupus erythematosus. J Immunol. 2007;178(10):6624-6633

34. Wu YC, Kipling D, Dunn-Walters DK. The relationship between CD27 negative and positive B cell populations in human peripheral blood. Front Immunol. 2011;2:81.

35. Fecteau JF, Côté G, Néron S. A new memory CD27- $\mathrm{IgG}^{+}$B cell population in peripheral blood expressing VH genes with low frequency of somatic mutation. J Immunol. 2006;177(6):3728-3736.

36. Bagnara D, et al. A reassessment of IgM memory subsets in humans. J Immunol. 2015;195(8):3716-3724.

37. Morbach H, et al. Activated memory B cells may function as antigen-presenting cells in the joints of children with juvenile idiopathic arthritis. Arthritis Rheum. 2011;63(11):3458-3466.

38. Yurasov S, et al. Defective B cell tolerance checkpoints in systemic lupus erythematosus. J Exp Med. 2005;201(5):703-711.

39. Isnardi I, et al. Complement receptor $2 / \mathrm{CD} 21^{-}$human naive B cells contain mostly autoreactive unresponsive clones. Blood. 2010;115(24):5026-5036.

40. Eris JM, Basten A, Brink R, Doherty K, Kehry MR, Hodgkin PD. Anergic self-reactive B cells present self antigen and respond normally to CD40-dependent T-cell signals but are defective in antigen-receptor-mediated functions. Proc Natl Acad Sci USA. 1994;91(10):4392-4396.

41. Jacobi AM, et al. Effect of long-term belimumab treatment on B cells in systemic lupus erythematosus: extension of a phase II, double-blind, placebo-controlled, dose-ranging study. Arthritis Rheum. 2010;62(1):201-210.

42. Lodolce JP, et al. African-derived genetic polymorphisms in TNFAIP3 mediate risk for autoimmunity. J Immunol. 2010;184(12):7001-7009.

43. Tavares RM, et al. The ubiquitin modifying enzyme A20 restricts B cell survival and prevents autoimmunity. Immunity. 2010;33(2):181-191.

44. Chen JM, et al. The association of CD40 polymorphisms with CD40 serum levels and risk of systemic lupus erythematosus. BMC Genet. 2015;16:121.

45. Vazgiourakis VM, et al. A common SNP in the CD40 region is associated with systemic lupus erythematosus and correlates with altered CD40 expression: implications for the pathogenesis. Ann Rheum Dis. 2011;70(12):2184-2190.

46. Katsiari CG, Liossis SN, Souliotis VL, Dimopoulos AM, Manoussakis MN, Sfikakis PP. Aberrant expression of the costimulatory molecule CD40 ligand on monocytes from patients with systemic lupus erythematosus. Clin Immunol. 2002;103(1):54-62

47. Matsuura JE, et al. Biophysical characterization of a soluble CD40 ligand (CD154) coiled-coil trimer: evidence of a reversible acid-denatured molten globule. Arch Biochem Biophys. 2001;392(2):208-218. 